\title{
A tungsten supplemented diet attenuates bacterial translocation in chronic portal hypertensive and cholestatic rats: role of xanthine dehydrogenase and xanthine oxidase
}

\author{
G Schimpl, M A Pabst, G Feierl, A Kuesz, H Özbey, S Takahashi, M E Höllwarth
}

\begin{abstract}
Background-Bacterial translocation (BT) plays a major role in the pathophysiological process of spontaneous infections in portal hypertension (PH) and cholestatic jaundice. The major mechanisms promoting BT in experimental animal models are the disruption of the intestinal ecological equilibrium and disruption of the intestinal mucosal barrier. The enzymes xanthine dehydrogenase (XD) and xanthine oxidase (XO) are often implicated as a significant source of oxidants which have a major impact on the impair-
\end{abstract} ment of intestinal barrier function.

$\mathrm{Aim}$ - To investigate the incidence of BT in rats with $\mathrm{PH}$ and obstructive jaundice, and to evaluate the impact of XD and XO. Methods-Animals were subjected to sham laparotomy (SL), PH by calibrated stenosis of the portal vein, and common bile duct ligation (CBDL). They were fed either a standard pellet diet or a tungsten supplemented molybdenum-free diet. Four weeks after the operative procedure, intestinal colonisation and BT to portal vein, vena cava, mesenteric lymph nodes, liver, and spleen were determined. Intestinal XD and XO activity were measured enzymatically and histochemically.

Department of Paediatric Surgery, University of Graz, Medical School,

Austria

G Schimpl

A Kuesz

H Özbey

S Takahashi

M E Höllwarth

Institute of Histology, University of Graz, Medical School, Austria

M A Pabst

Institute of Hygiene, University of Graz, Medical School, Austria

G Feierl

Correspondence to: Dr G Schimpl, Department of Paediatric Surgery, Auenbruggerplatz 34, A-8036 Graz, Austria.

Accepted for publication 23 June 1999 conversion may contribute to intestinal barrier failure in PH and after CBDL. (Gut 1999;45:904-910)

Keywords: bacterial translocation; portal hypertension; chronic cholestasis; xanthine oxidase; xanthine dehydrogenase

Spontaneous bacterial peritonitis, cholangitis, bacteriaemia, and sepsis are complications of portal hypertension $(\mathrm{PH})$ and obstructive jaundice which account for high morbidity and death rates. ${ }^{12}$ In most of these infectious episodes, the exact pathophysiological mechanism remains unclear. In recent years, the gut has been considered to be the major source of infection. $^{2}$ It was proposed that $\mathrm{PH}$ and jaundice may disrupt intestinal mucosal integrity and facilitate the egress of intraluminal intestinal bacteria to distant organs, a process termed bacterial translocation (BT). This process includes the steps of attachment of microbes to the gut mucosa, penetration through the epithelium into the lamina propria, and transport to distal sites. ${ }^{34}$

$\mathrm{PH}$, either isolated or as a sequel to liver disease, leads to severe alterations in intestinal perfusion. The increased splanchnic vascular resistance (backward flow theory) as well as an increased portal venous flow (forward flow theory) may cause intermittent intestinal mucosal hypoperfusion and hypoxia. ${ }^{5}{ }^{6}$ Hypoxia initiates oxidative damage of the intestinal integrity by increased conversion of the enzyme xanthine dehydrogenase (XD) to xanthine oxidase (XO). XD and XO are metalloflavoenzymes (four redox centres in the active site, molybdenum, two iron-sulphur clusters, and a flavin adenine dinucleotide centre) which are widely distributed among tissues of most species and are present in high concentrations in the intestinal epithelial cells. ${ }^{7-11}$ Under normal conditions, $\mathrm{XD}$ serves as a rate limiting step in nucleic acid degradation by catalysing the oxidation of hypoxanthine to xanthine and uric acid. In pathological conditions, XD can be converted into $\mathrm{XO}$ through reversible thiol oxidation or irreversible proteolytic modification. This XO has been shown to generate reactive oxygen species, superoxide and hydrogen peroxide, which are involved in the

Abbreviations used in this paper: $\mathrm{BT}$, bacterial translocation; SL, sham laparotomy; $\mathrm{PH}$, portal hypertension; CBDL, common bile duct ligation; $\mathrm{XO}$; xanthine oxidase; $\mathrm{XD}$, xanthine dehydrogenase. 
peroxidation damage of cells. ${ }^{791213}$ Mainly lipid peroxidation and activation of neutrophils are promoted by these oxygen derived free radicals which further ameliorate epithelial injury. ${ }^{14}$ In the intestinal tract, this epithelial injury may cause intestinal barrier failure, thus promoting BT.

In a previous study performed in portal hypertensive and common bile duct ligated rats, we were able to show that inhibition of XO by allopurinol can decrease the incidence of BT, attenuate intestinal mucosal lipid peroxidation (measured by intestinal mucosal malone dialdehyde levels), and reduce intestinal neutrophil derived myeloperoxidase activity. ${ }^{15}$

The aim of this study was to elucidate further the role of $\mathrm{XD}$ and $\mathrm{XO}$ in $\mathrm{BT}$ in chronic portal hypertensive and common bile duct ligated rats. In addition to the determination of intestinal bacterial colonisation and BT, we estimated XD and XO enzymatically and histochemically in the jejunum. Furthermore we examined the effect of a tungsten supplemented molybdenum-free diet. The result of feeding a diet containing tungsten is incorporation of wolfram instead of molybdenum into newly synthesised $\mathrm{XD}$ and $\mathrm{XO}$, resulting in progressive loss of oxidase activity. Complete inactivation of $\mathrm{XD}$ and $\mathrm{XO}$ can be achieved when tungsten is fed for more than 14 days. ${ }^{13} 16$ This diet has been used to ameliorate the deleterious effects of oxygen radicals generated by ischaemia-reperfusion in the intestinal tract. ${ }^{1617}$

\section{Methods}

Four week old male Sprague-Dawley rats (130-145 g body weight) were used for these experiments. The animals were purchased from Himberg Breeding Laboratories, Vienna, Austria. All experiments were conducted with the permission of the animal research commission of the Ministry of Science of Austria following local guidelines for the care and use of laboratory animals. The rats were housed in an environmentally controlled vivarium with a 12 hour light/dark cycle; they received a standard pellet diet and water ad libitum. Sixty animals were randomly assigned to one of three equal groups of 20 animals subjected to sham laparotomy (SL), $\mathrm{PH}$, or common bile duct ligation (CBDL). For all surgical procedures, anaesthesia was induced by intraperitoneal injection of $100 \mathrm{mg} / \mathrm{kg}$ ketamine.

Twenty rats in the SL group were anaesthetised, and under sterile conditions a $2 \mathrm{~cm}$ coeliotomy was performed. The portal vein and common bile duct were dissected free, and the abdominal wall was then closed in two layers with absorbable interrupted sutures.

Chronic $\mathrm{PH}$ was produced in 20 rats by calibrated stenosis of the portal vein as previously described. ${ }^{18}$ Briefly, the portal vein was dissected free, and a ligature of 3-0 silk was placed around the vein. A 20 gauge blunt needle was placed alongside the vein, and the ligature was tied snugly to the needle and vein. The needle was removed to yield a calibrated stenosis of the portal vein.

Twenty rats were subjected to obstructive jaundice induced by CBDL. The common bile duct was dissected free and double ligated with a 3-0 silk ligature. All ligatures were placed in the same position in all rats.

After the laparotomy all animals were placed in stainless steel molybdenum-free cages. Ten animals from each group were fed a standard pellet diet and water ad libidum and ten received a tungstate enriched normal protein diet (ICN Biochemicals Inc, Biochemical Division, Cleveland, Ohio, USA) and distilled water.

EXPERIMENTAL DESIGN

After four weeks, animals were weighed and reanaesthetised with ketamine, and a laparotomy from the xiphoid to the pubis was performed. Using sterile technique, the skin flaps were retracted and the abdominal muscles treated with $70 \%$ ethanol before the abdominal cavity was opened. Portal pressure was measured by cannulating the superior mesenteric vein with a 21 gauge needle connected to a manometer filled with saline, and the height of the right atrium was taken as zero reference level.

Blood samples were collected from the inferior vena cava for the measurement of total bilirubin, aspartate aminotransferase, alanine aminotransferase, alkaline phosphatase, and lactate dehydrogenase with a Cobas Mira multianalyser (Hoffmann LaRoche, Basel, Switzerland). Aliquots of $0.1 \mathrm{ml}$ of portal blood and inferior caval vein blood were plated on to blood agar. The central mesenteric lymph node complex was excised with sterile instruments. The liver and spleen were removed using separate instruments.

To measure intestinal colonisation, a $3 \mathrm{~cm}$ long piece of the jejunum was excised, opened on its antimesenteric border, and washed in sterile $0.9 \%$ saline. The mesenteric lymph node, parts of the liver, spleen, and ileum were weighed and placed in grinding tubes contain-

Table 1 Animal weight, portal pressure, total serum bilirubin and serum liver enzymes after sham laparotomy (SL), portal hypertension $(P H)$, and common bile duct ligation (CBDL) in untreated and tungsten supplemented (T) animals

\begin{tabular}{lllllll}
\hline & $S L$ & $P H$ & $C B D L$ & $S L+T$ & $P H+T$ & $C B D L+T$ \\
\hline Weight (g) & & & & & & \\
$\quad$ At the start & $130(10)$ & $140(10)$ & $145(10)$ & $140(10)$ & $135(10)$ & $140(10)$ \\
$\quad$ After 4 weeks & $350(120)$ & $330(10)$ & $330(20)$ & $340(15)$ & $315(20)$ & $295(20)$ \\
Bilirubin (mg/\%) & $0.23(0.1)$ & $0.22(0.2)$ & $15.1(2.7)^{\star}$ & $0.3(0.1)$ & $0.37(0.2)$ & $6.6(3.8)^{\star}+$ \\
AST (U/1) & $47(16)$ & $45(11)$ & $234(52)^{\star}$ & $37(4)$ & $34(10)$ & $171(28)^{\star} \dagger$ \\
ALT (U/1) & $33(15)$ & $24(5)$ & $118(35)^{\star}$ & $26(4)$ & $25(4)$ & $47(15)^{\star} \dagger$ \\
AP (U/1) & $231(41)$ & $288(45)$ & $599(71)^{\star}$ & $261(36)$ & $269(49)$ & $515(57)^{\star}$ \\
Portal pressure (mm Hg) & $7.4(1.1)$ & $19.9(2.1)^{\star}$ & $18.9(1.8)^{\star}$ & $7.2(0.5)$ & $18.7(2.2)^{\star}$ & $17.9(1.3)^{\star}$
\end{tabular}

AST, aspartate aminotransferase; ALT, alanine aminotransferase; AP, alkaline phosphatase.

${ }^{\star} \mathrm{p}<0.01 v \mathrm{SL} ; \mathrm{t}<<0.05 v$ untreated (no tungsten supplement). 
Table 2 fejunal colonisation with Gram negative and positive bacteria

\begin{tabular}{lllllll}
\hline & \multicolumn{2}{l}{ fejunal colonisation (log 10 per g tissue) } \\
\cline { 2 - 7 } & $S L$ & $P H$ & $C B D L$ & $S L+T$ & PH+T & $C B D L+T$ \\
\hline Gram positive & $3.1(1.3)$ & $4.4(1.4)^{\star \star}$ & $4.7(0.9)^{\star \star}$ & $3.4(1.1)$ & $4.2(0.5)^{\star \star}$ & $4.9(0.7)^{\star \star}$ \\
Gram negative & $2.4(0.6)$ & $2.6(0.4)$ & $3.6(0.7)^{\star \star}$ & $2.6(1.3)$ & $2.1(1.1)$ & $3.4(1.6)^{\star \star}$ \\
\hline
\end{tabular}

SL, sham laparotomy; PH, portal hypertension; CBDL, common bile duct ligation; +T, tungsten supplemented diet. ${ }^{\star \star} \mathrm{p}<0.01 v \mathrm{SL}$.

Table 3 Incidence of bacterial translocation

\begin{tabular}{|c|c|c|c|c|c|c|}
\hline & \multicolumn{6}{|c|}{ Incidence of bacterial translocation (number of positive cultures) } \\
\hline & $S L$ & PH & $C B D L$ & $S L+T$ & $P H+T$ & $C B D L+T$ \\
\hline Vena cava & & $1 / 10$ & $2 / 10$ & & $1 / 10$ & $1 / 9$ \\
\hline Vena porta & & $3 / 10$ & $5 / 10$ & & $1 / 10$ & $2 / 9$ \\
\hline MLN & $4 / 10$ & $5 / 10$ & $8 / 10$ & $2 / 10$ & $3 / 10$ & $4 / 9$ \\
\hline Liver & & $2 / 10$ & $9 / 10$ & & $1 / 10$ & $2 / 9$ \\
\hline Spleen & $2 / 10$ & $3 / 10$ & $3 / 10$ & $2 / 10$ & $1 / 10$ & $2 / 9$ \\
\hline Incidence (\%) & 12 & $28^{\star}$ & $54^{\star}$ & 8 & $14 \dagger$ & $28+$ \\
\hline Positive animals & 4 & 5 & 9 & 3 & 2 & 4 \\
\hline
\end{tabular}

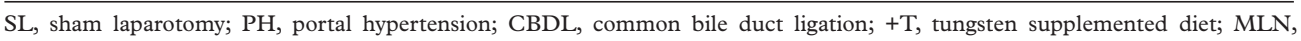
mesenteric lymph node.

${ }^{\star} \mathrm{p}<0.05 v \mathrm{SL} ; \dagger \mathrm{p}<0.05 v$ untreated (no tungsten supplement).

ing the 1:9 volume of sterile brain heart infusion (BioMerieux, Marcy l'Etoile, France), and homogenised with sterile ground glass stoppers. Serial dilutions of the homogenates were carried out, and $0.1 \mathrm{ml}$ of each dilution was plated on blood agar to culture for aerobic and facultative Gram positive cocci, on Endo agar to culture for aerobic and facultative Gram negative bacilli, and on MRS agar to culture for lactobacilli (Oxoid Co, London, $\mathrm{UK})$. All plates were incubated aerobically at $37^{\circ} \mathrm{C}$ for 48 hours. The plates were evaluated for bacterial growth by standard bacteriological techniques. Any growth of bacteria of the same biotype as cultured in the ileum was considered positive. Quantitative culture results were expressed as the number of colony forming units per $\mathrm{g}$ tissue $(\mathrm{CFU} / \mathrm{g})$, calculated from the dilutions of organ homogenates.

Enzymatic activities of $\mathrm{XO}$ and $\mathrm{XD}$ were determined spectrophotometrically in the jejunum (Spectronic 300 Arry; Milton-Roy Company, Brussels, Belgium) measuring the production of uric acid from xanthine. Briefly, the homogenised tissue was placed in $50 \mathrm{mM}$ potassium phosphate $(\mathrm{pH} 7.4)$ containing 0.25 $M$ sucrose, $1 \mathrm{mM}$ EDTA, $1 \mathrm{mM}$ dithiothreitol, and $0.2 \mathrm{mM}$ phenylmethanesulphonyl fluoride. The homogenates were centrifuged at $12000 \mathrm{rpm}$ for 20 minutes at $4^{\circ} \mathrm{C}$. The supernatants were used for measurement of $\mathrm{XO}+\mathrm{XD}$ and $\mathrm{XO}$. Uric acid formation per minute at $295 \mathrm{~nm}$ in the presence of either NAD or xanthine was determined. XD and XO activities were expressed as $\mathrm{mU} / \mathrm{g}$ dry weight of tissue samples. Dry weight of the jejunum was estimated by incubation of specimens of the jejunum for 48 hours at $50^{\circ} \mathrm{C}$.

The histochemical distribution of xanthine oxidoreductase in the jejunum was analysed by a modified histochemical method as described by Kooij. ${ }^{19}$ Briefly, specimens of the jejunum were immediately frozen in liquid nitrogen and stored at $-80^{\circ} \mathrm{C}$. Cryostat sections of $8 \mu \mathrm{m}$ thickness were cut at a cabinet temperature of $-25^{\circ} \mathrm{C}$ and incubated for 30 minutes at $37^{\circ} \mathrm{C}$ using an incubation medium containing $18 \%$ polyvinyl alcohol, $1.1 \mathrm{mM}$ tetranitroblue tetrazolium, $0.45 \mathrm{mM}$ 1-methoxyphenazine methosulphate and $0.5 \mathrm{mM}$ hypoxanthine. After incubation, the polyvinyl alcohol-containing medium was removed from the sections by rinsing for 10 seconds in $0.1 \mathrm{M}$ phosphate buffer. Sections were successively fixed in $4 \%$ formaldehyde in distilled water for five minutes at room temperature, washed in distilled water for one minute, and mounted in glycerol jelly. Sections were immediately evaluated by light microscopy and photographs of the sections were made because the final reaction product rapidly fades on exposure to light and heat.

STATISTICAL ANALYSIS

The results are expressed as mean (SD). Differences between the means of two groups were statistically tested using the MannWhitney $U$ test, and analysis of variance was used to compare more than two groups. $\mathrm{p}<0.05$ or less was considered significant in all analyses.

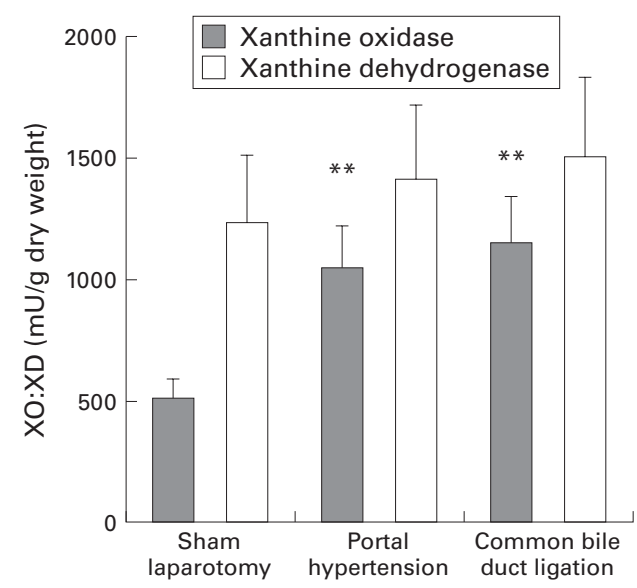

Figure 1 Xanthine oxidase (XO) and xanthine dehydrogenase (XD) activities in the jejunum of untreated rats subjected to sham laparotomy, portal hypertension, and common bile duct ligation. In all tungsten supplemented groups, no XO or XD activity was detected, indicating their complete inactivation. ${ }^{\star \star} p<0.01 v$ sham laparotomy. 

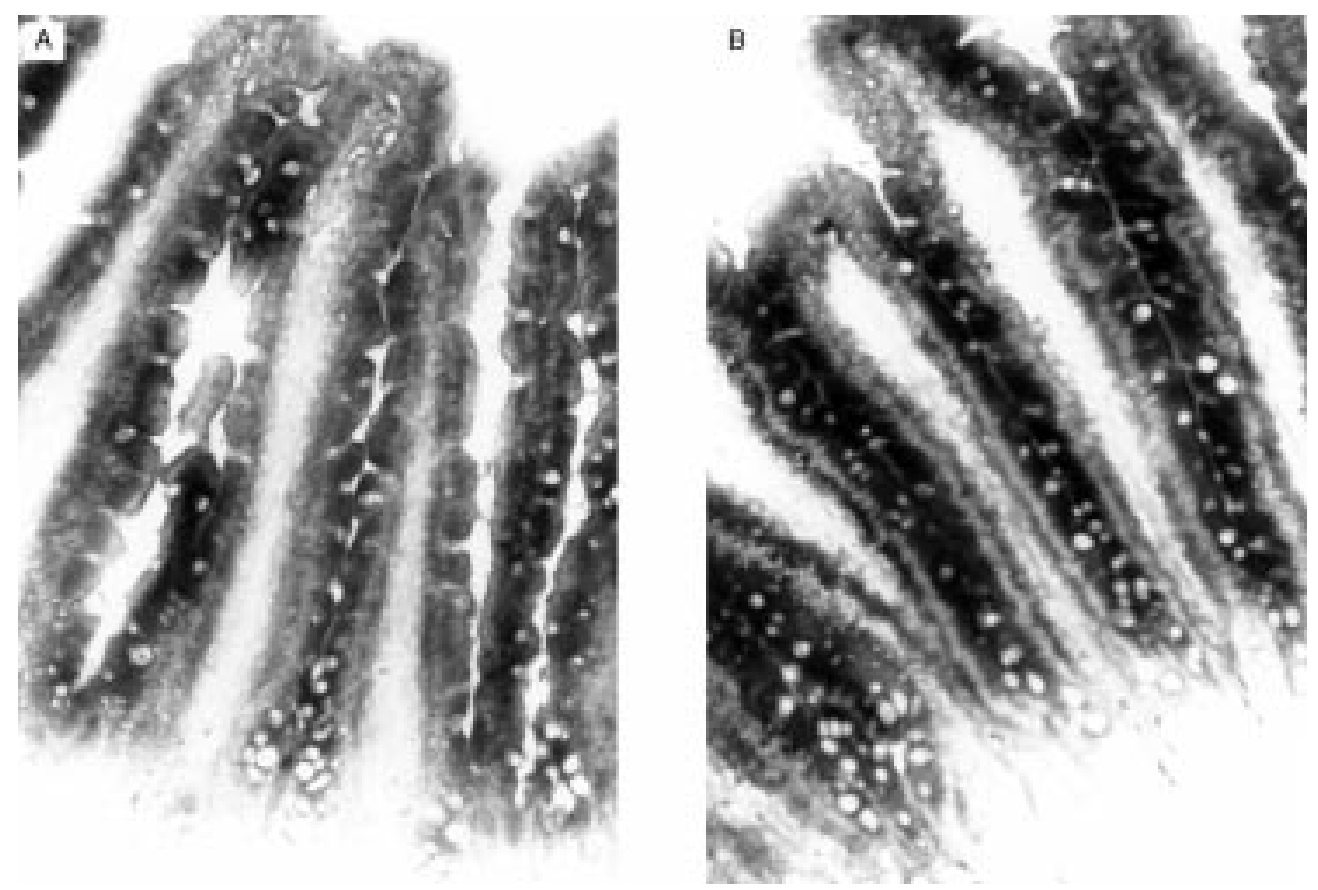

Figure 2 Histochemical distribution of xanthine oxidase in the jejunum of untreated animals. (A) sham laparotomy; (B) portal hypertension.

\section{Results}

After four weeks, 59 animals had survived the experiment. One rat with CBDL being fed the tungsten diet died on the 4 th postoperative day. Four animals, two with $\mathrm{PH}$, one after SL, and one with CBDL developed an incisional hernia. All sham operated animals had a patent portal vein and common bile duct. In rats with a calibrated portal vein stenosis, a stenotic but patent portal vein with dilated mesenteric veins was present. All animals with CBDL became visibly jaundiced with a cystic remnant of the common bile duct proximal to the ligatures. Table 1 summarises weight gain, portal pressure, and serum liver enzymes.

COLONISATION (TABLE 2)

Jejunal colonisation in all $\mathrm{PH}$ animals showed a significant Gram positive bacterial overgrowth when compared with the SL group $(p<0.05)$, and in all animals with CBDL a significant Gram positive and Gram negative bacterial overgrowth was seen. This bacterial overgrowth was related to greater jejunal colonisation with Escherichia coli, Streptococcus species, Lactobacilli, Pasteurella, and Proteus strains. There was no difference in jejunal colonisation between untreated $\mathrm{PH}$ and $\mathrm{CBDL}$ rats and $\mathrm{PH}$ and $\mathrm{CBDL}$ rats on the tungsten diet.

BACTERIAL TRANSLOCATION (TABLE 3)

In untreated and tungsten supplemented SL groups, BT occurred only to mesenteric lymph nodes and the spleen, with an incidence of $12 \%$ and $8 \%$ respectively. In untreated $\mathrm{PH}$ animals, the frequency of BT increased to $28 \%$, and it was mainly $E$ coli and Streptococci that were translocated ( $\mathrm{p}<0.05 v \mathrm{SL})$. Tungsten supplementation attenuated $\mathrm{BT}$ in $\mathrm{PH}$ animals to $14 \%$; only two animals from this group showed positive cultures compared to five animals in the normally fed PH group.
CBDL in untreated animals resulted in a BT rate of $54 \%$, and, in nine of 10 animals, translocated E coli, Streptococci, Proteus, and Pasteurella strains could be cultured $(\mathrm{p}<0.05 \mathrm{v}$ $\mathrm{SL}$ ). In the tungsten supplemented CBDL group, BT was found in $22 \%$ (four of nine animals) and this was significantly lower $(\mathrm{p}<0.05)$ than in the untreated CBDL group. $E$ coli and Streptococci were cultured most often. The mean number of translocating bacteria was $10^{2}$ $\mathrm{CFU} / \mathrm{g}$ tissue in the SL groups and this increased to $10^{3}$ and $10^{5} \mathrm{CFU} / \mathrm{g}$ tissue in the $\mathrm{PH}$ and CBDL groups respectively, with the highest number of bacteria cultured in samples of the portal vein and liver in untreated animals with CBDL.

\section{XO AND XD IN THE JEJUNUM}

Assays of $\mathrm{XO}$ and $\mathrm{XD}$ in the jejunum showed significantly $(\mathrm{p}<0.01)$ higher $\mathrm{XO}$ activity in untreated $\mathrm{PH}$ and CBDL animals than in the SL group (fig 1). As expected, in all tungsten supplemented animals, this treatment resulted in complete inactivation of $\mathrm{XO}$ and $\mathrm{XD}$, and all measured XO and XD levels were zero. On histochemical examination, large amounts of the final reaction product of $\mathrm{XO}$ and $\mathrm{XD}$ were found in the epithelial cells of the villi and crypts of the jejunum, and low but distinct amounts in Goblet's cells (fig 2). The layers beneath the epithelial lining did not show any enzyme activity. In histological sections from tungsten supplemented animals, no $\mathrm{XO}$ and $\mathrm{XD}$ activity could be found, confirming the results obtained enzymatically.

\section{Discussion}

In patients with $\mathrm{PH}$ or obstructive jaundice, an incidence of infectious complications of between $8 \%$ and $25 \%$ has been reported in the literature. ${ }^{12}{ }^{20}$ Spontaneous bacterial peritonitis, 
cholangitis, bacteriaemia, and sepsis account for death rates of up to $78 \%{ }^{12}$ Some $95 \%$ of these infections are caused by aerobic organisms normally present in the intestinal tract. ${ }^{21}$ However, in up to $30 \%$, no infective focus in patients with severe sepsis could be identified. ${ }^{12}{ }^{21}$ Recent studies have shown that $\mathrm{PH}$ and obstructive jaundice disrupt intestinal ecology and barrier function by producing structural changes in the bowel mucosa. The formation of portal systemic shunts, bacterial overgrowth resulting from the absence of intestinal bile flow, decreased bacterial clearance by the reticuloendothelial system, and impaired immunological defence are sequels to $\mathrm{PH}$ and/or cholestasis. ${ }^{32-26}$ These changes predispose to alterations in the intestinal ecology and the egress of bacteria from the intestinal tract to distant organs, a process termed BT. However, the exact mechanism leading to BT has not yet been clarified.

$\mathrm{PH}$, either isolated or as a sequel to liver disease, is characterised by a pathological increase in portal pressure and the formation of a network of portosystemic collaterals, diverting the portal blood stream to the systemic circulation. ${ }^{67} \mathrm{PH}$ further increases microvascular intestinal blood flow, but this is associated with a $41-51 \%$ decrease in intestinal arterial pressure, leading to intermittent intestinal mucosal hypoperfusion and abnormal tissue oxygenation. ${ }^{28}$ In particular, the microcirculatory architecture of the villus characterised by a single arteriole that passes unbranched from the submucosal plexus to the tip of the villus may act to increase the susceptibility of the epithelium to hypoxic injury. ${ }^{29}$ In such tissues, when intermittent hypoxia and reoxygenation is imposed, the enzyme XD can be converted into $\mathrm{XO}$, and $\mathrm{XO}$ from the inactive to the active form. ${ }^{9} 1630$

$\mathrm{XD}$ and $\mathrm{XO}$ are ubiquitous cytoplasmic molybdenum-containing enzymes which belong biochemically to the group of hydroxylases. ${ }^{11} 19$ They exist in separate but interconvertible forms, and the liver and intestine have the highest $\mathrm{XD} / \mathrm{XO}$ activity. ${ }^{9}$ Under physiological conditions, $\mathrm{XD} / \mathrm{XO}$ is involved in the degradation of alkaline phosphatase to urate by converting hypoxanthine via xanthine into uric acid. XD and XO also oxidise endogenous purines and pyrimidines. ${ }^{31}$ Normally, the XD form accounts for $80-96 \%$ of the enzyme, and only $4-20 \%$ is in the XO form. ${ }^{19}{ }^{32}$ Under various conditions, such as ischaemiareperfusion or infection, increased conversion of XD into XO occurs. Like XD, XO also oxidises accumulated hypoxanthine, but produces as a byproduct reactive oxygen metabolites such as oxygen radical, superoxide anions, and hydrogen peroxide. ${ }^{9}$ These reactive oxygen species have cytotoxic effects resulting from peroxidation of lipid components of epithelial cells and mitochondrial membranes which have the highest content of polyunsaturated fatty acids. ${ }^{33-36}$ Further, these reactive oxygen species act as chemoattractants for polymorphonuclear neutrophils by inducing extravasation of neutrophils from the bloodstream into the tissue. These neutrophils probably worsen tissue injury because of their ability to release toxic substances and activation of cytokines. $^{37} 38$

Many previous studies have documented that $\mathrm{XD} / \mathrm{XO}$ inhibition or inactivation under various pathological conditions successfully attenuates the generation of reactive oxygen species, reducing the extent of tissue injury. ${ }^{17} 3339$ We have shown in previous studies that competitive inhibition of XO with allopurinol in $\mathrm{PH}$ and after $\mathrm{CBDL}$ attenuated the incidence of BT, intestinal mucosal lipid peroxidation, and intestinal neutrophil derived myeloperoxidase activity. ${ }^{15}{ }^{40}$

In the present animal model of $\mathrm{PH}$ and CBDL, we particularly investigated the impact of intestinal XD and $\mathrm{XO}$ activities on intestinal bacterial colonisation and BT. In addition, we evaluated the effect of a tungsten supplemented molybdenum-free diet which has been reported to inactivate $\mathrm{XD}$ and $\mathrm{XO} .^{13}{ }^{17}$

To investigate possible changes in intestinal colonisation, we chose a segment of the jejunum and flushed it with sterile saline to remove non-adherent bacteria. Normally, this part of the intestine is sparsely populated with microbes, and it is believed that the magnitude of translocation is highly associated with bacterial density in the gut. ${ }^{41}$ Furthermore it has been suggested that attachment of bacteria is greater in the upper intestinal tract, and BT occurs to a slightly greater extent in the small intestine than in the colon. ${ }^{4}$ This could be, in part, because of a large surface area. $\mathrm{PH}$ and CBDL resulted in a significantly higher number of adherent bacteria in the jejunum but there was no difference in the type and number of bacteria cultured in the jejunum between normally fed and tungsten supplemented animals in this study. Whereas after CBDL the absence of intestinal bile, lack of secretory IgA, and impaired intestinal immunity are the possible causes of intestinal bacterial overgrowth, in $\mathrm{PH}$ the mechanisms promoting bacterial overgrowth are thought to be related to intestinal motor dysfunction and subsequent intestinal stasis. ${ }^{42-46} \mathrm{BT}$ occurred after SL in $12 \%$ of normally fed animals and $8 \%$ of the tungsten supplemented group. Positive cultures were only found in mesenteric lymph nodes and spleen. These incidences correspond to previous findings of BT in normal animals, and it is believed that this phenomenon of BT to lymph nodes and spleen is a normal process whereby gut associated lymphoid tissue samples foreign antigens. ${ }^{47}$ In $\mathrm{PH}$ in normally fed animals, a significant increase in BT was found in this study, indicating systemic invasion of enteric bacteria. In addition to bacteria in mesenteric lymph nodes and spleen, positive bacterial cultures could be obtained from the portal vein, vena cava, and liver.

Tungsten supplementation in PH resulted in lower incidences of BT without affecting the number of bacteria colonising the intestine. The same results for BT were found after CBDL, when nine of 10 untreated animals had a total of $54 \%$ of positive bacteriological cultures performed from the vena cava, portal vein, mesenteric lymph nodes, liver, and 
spleen. In the tungsten supplemented CBDL group, only four of nine animals showed a total of $22 \%$ of positive bacteriological cultures. Similarly to the $\mathrm{PH}$ groups, treatment did not influence the extent of bacterial overgrowth which was significantly higher than in the SL groups.

These findings suggest that intestinal bacterial overgrowth per se cannot be the single cause of $\mathrm{BT}$ in $\mathrm{PH}$ and CBDL. However, significantly higher numbers of viable bacteria were recovered from mesenteric lymph nodes, spleen, and lung of animals in which bacteria were injected into the upper intestinal tract than in those that received injection into the colon. ${ }^{4}$ This suggests that the lower part of the gut has a more efficient mechanism for killing translocating bacteria than the relatively clean upper intestinal tract, and that an increase in microbes in the jejunum may highly predispose to BT.

Enzymatic and histochemical determination of $\mathrm{XD}$ and $\mathrm{XO}$ in the jejunum showed a significant increase in XO in normally fed animals with $\mathrm{PH}$ and CBDL, but no significant changes in XD when compared with the SL group. This indicates an increased conversion and/or activation of $\mathrm{XO}$, possibly caused by altered perfusion of the intestine in $\mathrm{PH}$ and after CBDL. Whereas after SL, the percentage of jejunal $\mathrm{XO}$ to total $\mathrm{XO} / \mathrm{XD}$ was $28 \%$, it increased to $41 \%$ in $\mathrm{PH}$ and $44 \%$ after CBDL respectively. These results are in accord with reports in the literature, in which increased conversion of $\mathrm{XD}$ into $\mathrm{XO}$ under hypoxaemic conditions has been described. ${ }^{48-50}$ The tungsten supplemented molybdenum-free diet fed for 4 weeks completely inactivated XD and XO in normal, PH, and CBDL animals, and this was associated with significantly lower incidences of BT.

All these results were obtained in animal experiments, and it should be remembered that human $\mathrm{XD} / \mathrm{XO}$ activities are relatively low and vary individually compared with values in animals. ${ }^{9}{ }^{30}{ }^{51-53}$ However, preliminary results from a clinical study in children, in which we investigated intestinal $\mathrm{XO}$ and $\mathrm{XD}$ activities in gut specimens resected for various congenital or acquired diseases, showed quite high levels of $\mathrm{XD}$ and $\mathrm{XO}$ that were comparable with activities found in animals. A possible explanation for the differences between the reported low levels of $\mathrm{XD} / \mathrm{XO}$ in humans and our clinical study could be the fact that the reported levels of $\mathrm{XD} / \mathrm{XO}$ were determined post mortem whereas we were able to harvest specimens during surgery. ${ }^{52} 53$

Our findings support the thesis that bacterial species originating from the gut may be a significant source of infection in $\mathrm{PH}$ and obstructive jaundice. Inactivation of XD and $\mathrm{XO}$ by a tungsten supplemented diet resulted in a significant attenuation of BT in animals with $\mathrm{PH}$ and CBDL without influencing intestinal bacterial colonisation. Therefore high levels of XO in the intestine may contribute to intestinal barrier failure and promote BT by production of reactive oxygen species, activation of cytokines, and attraction of polymor- phonuclear neutrophils. Furthermore, XO inactivation seems to also have a beneficial effect on liver function in chronic cholestasis. In the tungsten supplemented CBDL group, significantly lower levels of serum bilirubin, aspartate aminotransferase and alanine aminotransferase were present than in the untreated $\mathrm{CBDL}$ group. This suggests that $\mathrm{XD}$ and $\mathrm{XO}$, heterogeneously distributed within the liver, may contribute to hepatocellular injury in chronic cholestasis. ${ }^{1454}$

However, the clinical relevance of this study remains speculative, firstly, because rats are very different with respect to the distribution of $\mathrm{XO}$ activity in the intestine, and secondly, because the side effects of long term $\mathrm{XD} / \mathrm{XO}$ inactivation have not yet been investigated. Further studies on BT in humans with $\mathrm{PH}$ or chronic cholestasis are warranted, especially with regard to the role of $\mathrm{XO}$ and its inhibition.

1 Gilgert JA, Kamath PS. Spontaneous bacterial peritonitis: an update. Mayo Clin Proc 1995;70:365-70.

2 Mihas AA, Toussaint J, Hsue HS, et al. Spontaneous bacterial peritonitis in cirrhosis: clinical and laboratory features, survival and prognostic factors. Hepatogastroenterology 1992;39:520-2.

3 Deitch EA, Sitting K, Li M, et al. Obstructive jaundice promotes bacterial translocation from the gut. Am f Surg 1990;159:79-84.

4 Fukushima R, Gianotti L, Alexander W. The primary site of bacterial translocation. Arch Surg 1994;129:53-8.

5 Benoit JN, Womach WA, Hernandez L. Forward and backward flow mechanisms of portal hypertension:relative contributions in the rat model of portal vein stenosis. Gastroenterology 1985;89:1092-6.

6 Vorobioff J, Bredfeldt JE, Groszmann RI. Hyperdynamic circulation in portal hypertensive rat model:a primary factor for maintenance of chronic portal hypertension. Am $\mathcal{F}$ Physiol 1983;244:G52-6.

7 McCord JM. Oxygen-derived free radicals in postischemic tissue injury. N Engl F Med 1985;312:354-64.

8 Liao XP, She YX, Liu SL, et al. Injurious effects of oxygen free radicals on human intestinal epithelial cells and their prevention. Pediatric Surgery International 1995;10:97-100.

9 Parks DA, Granger DN. Xanthine oxidase: biochemistry, distribution and physiology. Acta Physiol Scand 1986; 548(suppl):87-99.

10 Young CG. Models for the molybdenum hydroxylases. $\mathcal{f}$ Biol Chem 1997;2:810-16.

11 Russ H. The reaction mechanism of oxomolybdenum enzymes. Biochim Biophys Acta 1994;1184:143-69.

12 Xu P, Huecksteadt TP, Harrison R, et al. Molecular cloning, tissue expression of human xanthine dehydrogenase. Biochem Biophys Res Commun 1994;199:998-1004.

13 Topham RW, Jackson MR, Joslin SA, et al. Studies of the ferroxidase activity of native and chemically modified xanthine oxidoreductase. Biochem f 1986;235:39-44.

14 Muriel P, Suarez OR. Role of lipid peroxidation in biliary obstruction. F Appl Toxicol 1994;14:423-6.

15 Schimpl G, Pesendorfer P, Steinwender G, et al. Allopurinol reduces bacterial translocation, intestinal mucosal lipid peroxidation, and neutrophil-derived myeloperoxidase activity in chronic portal hypertensive and common bile duct-ligated growing rats. Pediatr Res 1996;40:422-8.

16 Johnson LJ, Waud WR, Rajagopalan KV, et al. Molecular basis of the biological function of molybdenum: molybdenum-free xanthine oxidase from the liver of tungsten-treated rats. F Biol Chem 1974;249:5056-61.

17 Parks DA, Buckley GB, Granger DN. Role of oxygenderived free radicals in digestive tract diseases. Surgery 1983;94:415-22.

18 Choijker M, Groszmann RJ. Measurement of portalsystemic shunting in the rat using $\chi$-labeled microspheres. Am 7 Physiol 1981;240: G371-5.

19 Kooij A. A re-evaluation of the tissue distribution and physiology of xanthine oxidoreductase. Histochem $\mathcal{F} 1994$; 26:889-915.

20 O’Boyle CJ, MacFie J, Mitchell CJ, et al. Microbiology of gut translocation in humans. Gut 1998;42:29-35.

21 Garcia-Tsao G. Spontaneous bacterial peritonitis. Gastroenterol Clin North Am 1992;21:257-75.

22 Reynolds JV, Murchan P, Redmond HP, et al. Failure of macrophage activation in experimental obstructive aundice: association with bacterial translocation. Brf Surg 1995;82:543-8.

23 Garcia-Tsao G, Albillos A, Barden GE, et al. Bacterial translocation in acute and chronic portal hypertension. Hepatology 1993; 17:1081-5.

24 Ding JW, Andersson R, Soltesz V, et al. The role of bile and bile acids in bacterial translocation in obstructive jaundice. Eur F Surg 1993;25:11-19.

25 Alexander JW. Nutrition and translication. Fournal of Parenteral and Enteral Nutrition 1990;14:170-4. 
26 Basista MH, Stauber RE, van Thiel DH, et al. Effects of isolated portal hypertension on Kunffer cell function. Dig Dis lated portal hyperte

27 Blanchet L, Lebrec D. Changes in splanchnic blood flow in portal hypertensive rats. Eur $\mathcal{F}$ Clin Invest 1982;12:327-31.

28 Moreau R, Lee SS, Soupison T, et al. Abnormal tissue oxygenation in patients with cirrhosis and liver failure. F Hepatol 1998;7:98-105.

29 Aranow JS, Fink MP. Determinants of intestinal barrier failure in critical illness. Br $\mathcal{F}$ Anaesth 1996;77:71-81.

30 Moriwaki Y, Yamamoto T, Yamakita JI, et al. Comparative localisation of aldehyde oxidase and xanthine oxidoreductase activity in rat tissues. F Histochem 1998;30:69-74

31 Van den Munckhof RJM, Vreeling-Sinderarova H, Schellens JM, et al. Ultrastructural localization of xanthine oxidase in the digestive tract of the rat 7 Histochem 1995;27:897-905.

32 Frederiks WM, Bosch KS. The proportion of xanthine oxidase activity to total xanthine oxidoreductase activity in situ remains constant in rat liver under various (patho) physiological conditions. Hepatology 1996;24:1179-84.

33 Granger DN, Höllwarth ME, Parks DA. Ischemiareperfusion iniury: role of oxygen-derived free radicals. reperfusion injury: role of oxygen-derived

34 Tripple DL, Yee AW, Jones DP. The pathophysiological significance of lipid peroxidation in oxidative cell injury. Hepatology 1979; 7:377-87.

35 Parola M, Leonarduzzi G, Robino G, et al. On the role of lipid peroxidation in the pathogenesis of liver damage induced by long-standing cholestasis. Free Radic Biol Med 1996;20:351-9.

36 Kato S, Kawase T, Alderman J. Role of xanthine oxidase in ethanol-induced lipid peroxidation in rats. Gastroenterology 1990;98:203-10.

37 Weiss SJ. Tissue destruction by neutrophils. $N$ Engl $\mathcal{F}$ Med 1989;320:365-76.

38 Spitzer JA, Mayer AMS. Hepatic neutrophil influx: eicosanoid and superoxide formation in endoxemia. 7 Surg Res 1993;55:60-7.

39 Grisham MB, Hernandez LA, Granger DN. Xanthine oxidase and neutrophil infiltration in intestinal ischemia. Am $\mathcal{f}$ Physiol 1986;251: G567-74.

40 Schimpl G, Höllwarth ME, Khoschsorur G, et al. Effect of a portojugular shunt and allopurinol on bacterial transloca- tion induced by temporary portal vein occlusion. Pediatric Surgery International 1994;9:254-7.

41 Dickmann MD, Chappelka AR, Schaedler RW. The microbial ecology of the upper small bowel. Am $\mathcal{f}$ Gastroenterol 1976;65:57-62

42 Llovet JM, Bartoli R, Planas R, et al. Bacterial translocation in cirrhotic rats. Its role in the development of spontaneous bacterial peritonitis. Gut 1994;35:1648-52.

43 Rimola A, Soto R, Bory F, et al. Reticuloendothelial system phagocytic activity in cirrhosis and ist relation to bacterial infections and prognosis. Hepatology 1984;4:53-8.

44 Slocum MM, Sittig KM, Specian RD, et al. Absence of intestinal bile promotes bacterial translocation. Am Surg intestinal bile pron

45 Jacobs DL, Spanta AD, Quigley EMM, et al. The effect of mesenteric venous hypertension on gut motility and absorbtion. I Surg Res 1990;48:561-7.

46 Reilly JA, Quigley EMM, Forst CF, et al. Small intestinal transit in the portal hypertensive rat. Gastroenterology 1991; 100:670-4.

47 Berg RD, Garlington AW. Translocation of certain indigenous bacteria from the gastrointestinal tract to the mesenteric lymph nodes and other organs in a gnotobiotic mouse model. Infect Immun 1979;23:403-11.

48 Miller DM, Grover TA, Nayini A, et al. Xanthine oxidase: an iron-dependent lipid peroxidation. Arch Biochem Biophys 1993;301:1-7

49 Saugstad OD. Role of xanthine oxidase and its inhibitor in hypoxia: reoxygenation injury. Pediatrics 1996;98:103-7.

50 Parks DA, Williams TK, Beckmann JS. Conversion of xanthine dehydrogenase to xanthine oxidase in ischemic rat intestine. Am F Physiol 1988;254:G768-74

51 Moriwaki Y, Yamamoto T, Yamaguchi K, et al. Immunohistochemical localisation of xanthine oxidase in human tissues. Acta Histochem Cytochem 1996;29:153-62.

52 Wajner M, Harkness RA. Distribution of xanthine dehydrogenase and oxidase activities in human and rabbit tissues. Biochim Biophys Acta 1989;991:79-84.

53 Vettenranta K, Raivio KO. Xanthine oxidase during human fetal development. Pediatr Res 1990;27:286-8.

54 Lemaster JJ, Nieminen AL. Mitochondral oxygen radical formation during reductive and oxidative stress to intact hepatocytes. Biosci Rep 1997;17:281-91. 